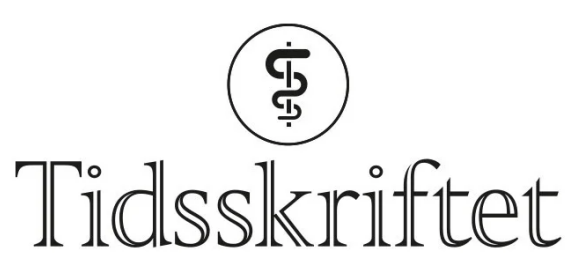

DEN NORSKE LEGEFORENING

\title{
Blir retningslinjer for behandling av mindre alvorlige hodeskader fulgt?
}

KORT RAPPORT

\section{KJELL ALEXANDER THUNES AKRE}

Nevro-, ortopedi- og rehabiliteringsklinikken Universitetssykehuset Nord-Norge, Troms $\emptyset$

Han har bidratt med idé, design, datainnsamling, tolking av data, utarbeiding av resultatpresentasjon, diskusjon og konklusjon samt godkjenning av manus. Kjell Alexander Thunes Akre er lege i spesialisering i nevrokirurgi.

Forfatteren har fylt ut ICMJE-skjemaet og oppgir ingen interessekonflikter.

\section{TOR INGEBRIGTSEN}

tor.ingebrigtsen@unn.no Institutt for klinisk medisin UiT - Norges arktiske universitet

og

Nevro-, ortopedi- og rehabiliteringsklinikken

Universitetssykehuset Nord-Norge, Troms $\emptyset$

Han har bidratt med idé, design, tolking av data, utarbeiding av resultatpresentasjon, diskusjon og konklusjon samt godkjenning av manus.

Tor Ingebrigtsen er spesialist i nevrokirurgi, professor og overlege.

Forfatteren har fylt ut ICMJE-skjemaet og oppgir følgende interessekonflikter: Han har vært involvert $\mathrm{i}$ utviklingen av de skandinaviske retningslinjene for håndtering av voksne med minimale, lette og moderate hodeskader.

\section{BAKGRUNN}

De skandinaviske retningslinjene for akutt håndtering av voksne med minimal, lett eller moderat hodeskade har som mål å identifisere pasienter med risiko for å utvikle intrakranialt hematom samt å unngå unødvendig computertomografi (CT) og sykehusinnleggelse. Vi undersøkte etterlevelsen av retningslinjene ved Universitetssykehuset Nord-Norge Tromsø.

\section{MATERIALE OG METODE}

Et søk i det pasientadministrative systemet identifiserte 448 pasienter med diagnosekode for hodeskade. Vi ekskluderte 298 som oppfylte ett eller flere eksklusjonskriterier, og inkluderte 150 med minimal, lett eller moderat skade i en retrospektiv undersøkelse. Håndteringen ble kategorisert til enten å være i henhold til retningslinjene eller ikke. Vi definerte manglende etterlevelse som overdiagnostikk (unødvendig CT og/eller innleggelse) eller underdiagnostikk (nødvendig CT og/eller innleggelse ikke gjennomført). 
Håndteringen var i henhold til retningslinjene for 96/150 (64\%) pasienter. Andelen økte med alvorlighetsgraden (minimal 4/12 (33\%), lett 76/119 (64\%) og moderat skade 16/19 $(84 \%)) \cdot 54 / 150$ (36\%) pasienter ble ikke håndtert i henhold til retningslinjene. Dette skyldtes unødvendig CT og/eller innleggelse hos 39/54 (72\%) og underdiagnostikk hos 15/54 $(28 \%)$ pasienter. Blant pasienter med lett hodeskade med lav risiko fikk $35 / 57$ (61\%) analysert hjerneskademarkøren S10oB, som anbefalt.

FORTOLKNING

Etterlevelsen av de skandinaviske retningslinjene kan bli bedre.

\section{HOVEDFUNN}

Overfor 96 av 150 (64\%) pasienter behandlet ved Universitetssykehuset Nord-Norge Troms $\emptyset$, fulgte man de skandinaviske retningslinjene for håndtering av pasienter med minimal, lett og moderat hodeskade.

Overdiagnostikk med (ikke anbefalt) CT ble utført hos 30 av 150 (20\%) pasienter, og var den vanligste årsaken til manglende etterlevelse.

De fleste pasienter med hodeskade er ved bevissthet ved første vurdering. Målet med den akutte håndteringen er å identifisere pasienter med risiko for å utvikle traumatisk intrakranialt hematom, men også å unngå unødvendig computertomografi (CT) eller sykehusinnleggelse.

Scandinavian Neurotrauma Committee (SNC) publiserte retningslinjer for akutt håndtering av voksne med minimal, lett eller moderat hodeskade i 2013 (1). En litteraturoppsummering vurderte kvaliteten hos ti retningslinjer etter Appraisal of Guidelines for Research and Evaluation (AGREE) II-kriteriene, og fant at de skandinaviske retningslinjene var blant de tre som best oppfylte kriteriene (므). En validering av fem retningslinjer viste at de skandinaviske retningslinjene hadde god balanse mellom sensitivitet og spesifisitet og dermed ga størst reduksjon i bruken av CT, uten at intrakraniale hematomer ble oversett (3).

Det foreligger $\emptyset$ kende bekymring for at ioniserende stråling selv i moderate doser kan forårsake kreft (4). Strålevernmyndighetene har uttrykt bekymring for økende bruk av CT i Norge. Målet med denne studien var derfor å undersøke etterlevelsen av de skandinaviske retningslinjene ved Universitetssykehuset Nord-Norge Tromsø.

\section{Materiale og metode}

Universitetssykehuset Nord-Norge Tromsø er lokalsykehus for 167202 innbyggere i Troms (2018). De fleste hodeskader vurderes ved lokal legevakt og henvises videre til sykehus hvis skadegraden vurdert etter de skandinaviske retningslinjene er mer alvorlig enn minimal (1). Akuttmedisinsk kommunikasjonssentral kan ved henvendelse til medisinsk nødtelefon beslutte direkte transport til sykehus ved mistanke om alvorlig hodeskade.

I akuttmottaket gjennomføres triage av sykepleier. Pasienter med skår >13 på Glasgowskalaen (Glasgow Coma Scale, GCS) uten fokalnevrologiske utfall utredes av lege i spesialisering (LIS) i generell kirurgi, mens pasienter med GCS-skår $\leq 13$ og/eller fokalnevrologiske utfall utredes av LIS-lege i nevrokirurgi. Sykehuset utfører CT og analyse av hjerneskademarkøren S1ooB, som frigjøres til blodet ved skade av gliaceller. I retningslinjene til Scandinavian Neurotrauma Committee anbefales prøven som et alternativ til CT ved lett hodeskade med lav risiko (figur 1). 


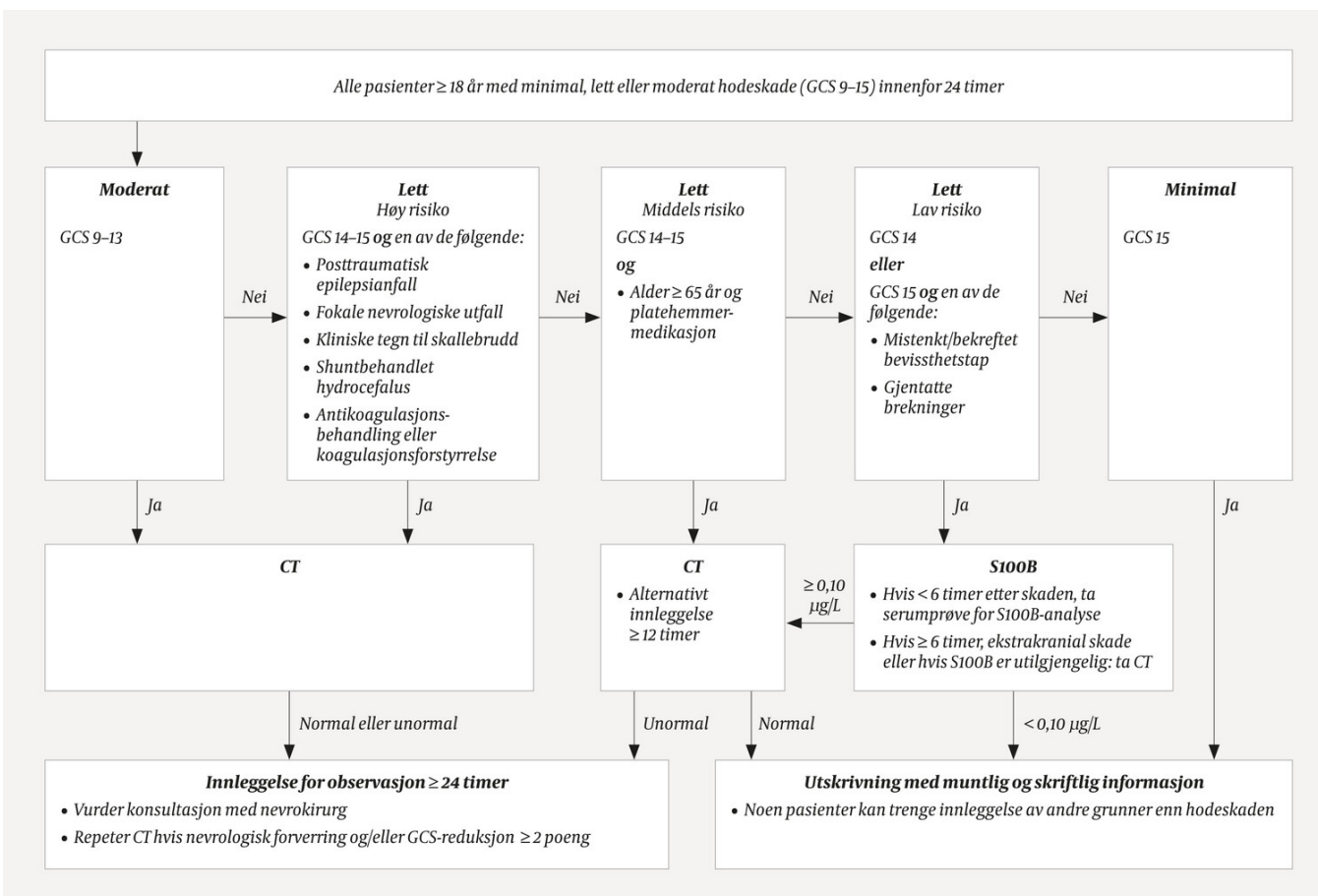

Figur 1 Flytskjema for akutt håndtering av voksne pasienter med minimal, lett eller moderat hodeskade (1).

Vi gjennomførte en studie av alle voksne pasienter med minimal, lett eller moderat hodeskade vurdert i akuttmottaket i perioden 1.9.2018-31.8.2019. Et søk i det pasientadministrative systemet identifiserte 448 pasienter med ICD 10-diagnosekode for hodeskade. Vi inkluderte 150 pasienter $\geq 18$ år som ble vurdert innen 24 timer. 298 pasienter ble ekskludert fordi de enten hadde alvorlig hodeskade (GCS-skår <9), mangelfull journaldokumentasjon slik at GCS-skår ikke kunne beregnes $(n=8)$, ikke hadde hodeskade (feilkodet) eller fordi de ble mottatt etter utløsing av traumealarm etter kriteriene i nasjonalt traumesystem (disse håndteres etter andre retningslinjer).

Vi gjorde en retrospektiv gjennomgang av pasientjournalene. Følgende ble registrert: alder og kjønn, relevant tidligere sykdom, bruk av antikoagulantia og platehemmere, skadehistorie (bevissthetstap, kvalme/brekninger og krampeanfall etter skaden) og funn ved klinisk undersøkelse (GCS-skår, fokalnevrologiske utfall og kliniske tegn til skallebrudd).

Hos 42 pasienter der GCS-skår ikke var nedtegnet, beregnet vi skår ut fra journalopplysninger om åpning av øynene samt motorisk og verbal respons. Vi registrerte også informasjon om hvorvidt CT og/eller analyse av S1ooB var gjennomført, og i så fall med hvilke funn, og om pasienten hadde vært innlagt til observasjon. Håndteringen ble kategorisert til enten å være i henhold til de skandinaviske retningslinjene eller ikke (figur 1). Vi definerte manglende etterlevelse som overdiagnostikk (unødvendig CT-undersøkelse og/eller innleggelse) eller underdiagnostikk (nødvendig CT-undersøkelse og/eller innleggelse ikke gjennomført).

Undersøkelsen var godkjent av personvernombudet som et kvalitetssikringsprosjekt (nr. 02344).

\section{Resultater}

De 150 inkluderte pasientene hadde gjennomsnittsalder 50 år (spredning 18-94), og 97 (65\%) var menn. 12/150 (8\%) hadde minimal skade, 119/150 (79\%) lett skade og 19/150 (13\%) hadde moderat skade. 120/150 (80\%) pasienter ble unders $\varnothing$ kt med CT, 93/150 (62 \%) ble innlagt til observasjon og 50/150 (33\%) fikk utført analyse av S10o B. 
Håndteringen var i henhold til de skandinaviske retningslinjene for 96/150 (64\%) pasienter. Andelen $\emptyset$ kte med alvorlighetsgraden (minimal skade 4/12 (33\%), lett skade 76/119 (64\%) og moderat skade $16 / 19(84 \%))$. Tabell 1 viser fordelingen av årsaker til at retningslinjene ikke ble etterlevd.

\section{Tabell 1}

Fordeling av over- og underdiagnostikk hos 54/150 (36\%) pasienter som ikke ble håndtert i henhold til skandinaviske retningslinjer for akutt håndtering av voksne pasienter med minimal, lett eller moderat hodeskade (1). Overdiagnostikk = unødvendig CT-unders økelse og/eller innleggelse. Underdiagnostikk = nødvendig CT-undersøkelse og/eller innleggelse ikke gjennomført. $\mathrm{CT}=$ computertomografi.

\begin{tabular}{|rrr|}
\hline Diagnostikk & $\mathbf{N}(\%)$ \\
\hline Overdiagnostikk & \\
\hline CT & $24(44)$ \\
\hline Innleggelse & $9(17)$ \\
\hline CT og innleggelse & $6(11)$ \\
\hline Underdiagnostikk & $4(7)$ \\
\hline CT & $9(17)$ \\
\hline Innleggelse & $2(4)$ \\
\hline CT og innleggelse & $54(100)$ \\
\hline
\end{tabular}

Blant pasienter med lett hodeskade med lav risiko fikk 35/57 (61\%) analysert S1ooB som anbefalt. Serumnivået av S10oB var $\geq 0,10 \mu \mathrm{g} / \mathrm{L}$ hos 20/35 (57\%), og 17/20 (85\%) av disse ble undersøkt med CT. Blant 15/35 (43\%) med S10oB < 0,10 $\mu \mathrm{g} / \mathrm{L}$ ble én pasient undersøkt med CT. Det ble gjennomført analyse av S10oB uten at dette er anbefalt hos 15/150 (10 \%) pasienter, fordelt på 6/15 (40\%) med minimal skade, 7/15 (47\%) med lett skade og middels eller høy risiko og 2/15 (13\%) med moderat skade.

\section{Diskusjon}

Undersøkelsen viser at håndteringen av minimale, lette og moderate hodeskader var i henhold til retningslinjene for om $\operatorname{lag}^{2} / 3$ av pasientene. Overdiagnostikk med (ikke anbefalt) CT ble utført hos 30 av 150 (20\%) pasienter, og var den vanligste årsaken til avvik. Dette påfører en liten, men ikke neglisjerbar risiko knyttet til ioniserende stråling. Samtidig ble anbefalt CT og/eller innleggelse til observasjon ikke gjennomført for 15 av 150 (10\%) pasienter. Med det følger en liten risiko for å overse alvorlig intrakranial skade.

Undersøkelsen viser også at analyse av S1ooB ble gjennomført som anbefalt hos nærmere $2 / 3$ når hodeskaden ble kategorisert som lett med lav risiko. Analysen var negativ hos 15 av 35 (43\%) pasienter, som dermed ble spart for en CT-undersøkelse som ellers ville blitt gjennomført. Bedre implementering kan bidra til ytterligere reduksjon av antall CTundersøkelser. 
Vår undersøkelse er gjennomført i rutinemessig klinisk praksis flere år etter implementering av retningslinjene. Den er sannsynligvis representativ for rutinemessig praksis både ved Universitetssykehuset Nord-Norge Tromsø og andre norske sykehus. Det er en svakhet at vi ekskluderte 298 pasienter uten å dokumentere fordelingen på eksklusjonskriteriene. Dette medfører en liten risiko for seleksjonsskjevhet. Vi identifiserte pasienter med et bredt søk som inkluderte alle diagnosekoder for hodeskade. De fleste ble ekskludert på grunn av alder under 18 år, at det var gått mer enn 24 timer fra skadetidspunkt til vurdering eller at det forelå multitraume.

Heskestad og medarbeidere unders $ø$ kte pasienter behandlet ved Stavanger universitetssjukehus i 2003-04 og 2005-09 og fant at henholdsvis 259/508 (51\%) og 738/1 180 (63\%) pasienter ble håndtert i henhold til retningslinjene $(5, \underline{6})$. Dette samsvarer med våre funn. Systematiske kunnskapsoppsummeringer viser stor variasjon i, og mange årsaker til, manglende etterlevelse (7.). Personlige forhold knyttet til legens kunnskaper og holdninger, egenskaper ved retningslinjene (tilgjengelighet og praktisk anvendbarhet) samt ytre forhold som tilgang til ressurser og samarbeidsforhold i sykehuset påvirker etterlevelsen $(\underline{8})$.

Tiltak for bedre etterlevelse må sannsynligvis baseres på kvalitative undersøkelser av årsaker til avvik ved det enkelte sykehus. Ledelsesforankring, opplæring av nyansatte, sjekklister innarbeidet i arbeidsflyten i den elektroniske pasientjournalen og tilrettelegging av praktiske rutiner slik at disse er i overensstemmelse med anbefalingene i retningslinjene, er sannsynligvis avgjørende ( $\underline{8})$.

Artikkelen er fagfellevurdert.

\section{LITTERATUR}

1. Sundstrøm T, Wester K, Enger M et al. Skandinaviske retningslinjer for akutt håndtering av voksne pasienter med minimal, lett eller moderat hodeskade. Tidsskr Nor Legeforen 2013; 133: E1-6. [PubMed] [CrossRef]

2. Di BS, Wei M, Ma WJ et al. A critical review to traumatic brain injury clinical practice guidelines. Medicine (Baltimore) 2019; 98: e14592. [PubMed][CrossRef]

3. Svensson S, Vedin T, Clausen L et al. Application of NICE or SNC guidelines may reduce the need for computerized tomographies in patients with mild traumatic brain injury: a retrospective chart review and theoretical application of five guidelines. Scand J Trauma Resusc Emerg Med 2019; 27: 99. [PubMed][CrossRef]

4. Davis F, Il'yasova D, Rankin K et al. Medical diagnostic radiation exposures and risk of gliomas. Radiat Res 2011; 175: 790-6. [PubMed][CrossRef]

5. Heskestad B, Baardsen R, Helseth E et al. Guideline compliance in management of minimal, mild, and moderate head injury: high frequency of noncompliance among individual physicians despite strong guideline support from clinical leaders. JTrauma 2008; 65: 1309-13. [PubMed][CrossRef]

6. Heskestad B, Waterloo K, Ingebrigtsen T et al. An observational study of compliance with the Scandinavian guidelines for management of minimal, mild and moderate head injury. Scand J Trauma Resusc Emerg Med 2012; 20:32. [PubMed][CrossRef]

7. Arts DL, Voncken AG, Medlock S et al. Reasons for intentional guideline non-adherence: A systematic review. Int J Med Inform 2016; 89: 55-62. [PubMed][CrossRef]

8. Fischer F, Lange K, Klose K et al. Barriers and strategies in guideline implementation - a scoping review. Healthcare (Basel) 2016; 4:36. [PubMed][CrossRef]

Publisert: 3. mai 2021. Tidsskr Nor Legeforen. DOI: 10.4045/tidsskr.20.0986

Mottatt 30.11.2020, første revisjon innsendt 8.2.2021, godkjent 25.2.2021.

Publisert under åpen tilgang CC BY-ND. Lastet ned fra tidsskriftet.no 26. april 2023. 